\title{
Blood-Brain Barrier Permeability Correlates with Medial Temporal Lobe Atrophy but Not with Amyloid- $\beta$ Protein Transport across the Blood-Brain Barrier in Alzheimer's Disease
}

\author{
Yasuko Matsumoto Daisuke Yanase Moeko Noguchi-Shinohara Kenjiro Ono \\ Mitsuhiro Yoshita Masahito Yamada \\ Department of Neurology and Neurobiology of Aging, Kanazawa University Graduate School of Medical Science, \\ Kanazawa, Japan
}

\section{Key Words}

Alzheimer's disease $\cdot$ Blood-brain barrier $\cdot$ Medial temporal lobe atrophy $\cdot$ Amyloid $-\beta$ protein

\begin{abstract}
Background/Aims: Alterations in the blood-brain barrier (BBB) may play an important role in the pathogenesis and treatment of Alzheimer's disease (AD). We investigated BBB disturbance and its influence on the equilibrium of amyloid$\beta$ protein $(A \beta)$ between plasma and cerebrospinal fluid (CSF) in AD patients. Methods: We analyzed albumin ratio as a marker of the BBB permeability and correlated it with the severity of dementia, brain atrophy on MRI, apolipoprotein $E$ isoform, CSF levels of total tau, CSF and plasma levels of $A \beta$ 1-40 $\left(A \beta_{40}\right)$ and 1-42 $\left(A \beta_{42}\right)$, and CSF/plasma ratios of $A \beta_{40}$ and $A \beta_{42}$ in $42 A D$ patients. Results: The albumin ratio was positively correlated with the severity of medial temporal lobe atrophy but not with the other parameters including CSF/plasma ratios of $A \beta_{40}$ or $A \beta_{42}$. Conclusion: Our results suggest that progression of medial temporal lobe atrophy is associated with increased $B B B$ permeability and that the transport of $A \beta$ across the $B B B$ is not influenced by the $B B B$ alteration in AD.

Copyright $\odot 2007$ S. Karger AG, Basel
\end{abstract}

\section{Introduction}

Alzheimer's disease (AD) is the most common cause of dementia in the elderly. The pathogenesis of this disease has not yet been fully elucidated. Several studies have been performed to investigate whether blood-brain barrier (BBB) alterations play a significant role in $\mathrm{AD}$ [1-11]. Despite morphological evidence suggesting abnormalities of the brain microvasculature that constitutes the $\mathrm{BBB}$ in $\mathrm{AD}$ [2], there is still little clinical evidence supporting $\mathrm{BBB}$ disruption in $\mathrm{AD}$ patients [1, 3-5, 7-11]. Understanding of the $\mathrm{BBB}$ alteration is important because it may influence the regulation of entry of plasma-derived amyloid- $\beta$ protein $(A \beta)$ into the brain as well as the clearance of brain-derived $A \beta$. Changes in BBB permeability may also affect the delivery of anti-AD drugs into the brain.

In the present study, we investigated the cerebrospinal fluid (CSF)/serum albumin ratio, a marker of BBB permeability, and correlated it with dementia scales, brain atrophy on magnetic resonance imaging (MRI), apolipoprotein E (ApoE) isoform, CSF levels of total tau, CSF and plasma levels of $A \beta$ and CSF/plasma ratios of $A \beta$ in $A D$ patients.

\section{KARGER}

Fax +41613061234 E-Mail karger@karger.ch www.karger.com
Prof. Masahito Yamada

Department of Neurology and Neurobiology of Aging

Kanazawa University Graduate School of Medical Science

13-1, Takara-machi, Kanazawa, Ishikawa 920-8640 (Japan)

Tel. +81 76265 2290, Fax +81 76234 4253, E-Mail m-yamada@med.kanazawa-u.ac.jp 
Table 1. Clinical features, brain atrophy, and albumin, total tau, $\mathrm{A} \beta_{42}$ and $\mathrm{A} \beta_{40}$ in CSF and serum/plasma in 42 patients with $\mathrm{AD}$

\begin{tabular}{lcc}
\hline & Range & Mean \pm SD \\
\hline Age, years & $53-81$ & $69.9 \pm 7.9$ \\
CDR & $0.5-3$ & $1.0 \pm 0.7$ \\
MMSE & $9-27$ & $20.8 \pm 4.7$ \\
MTA $^{1}$ & $0-4$ & $2.0 \pm 1.0$ \\
Serum albumin, mg/dl & $12.4-39.3$ & $25.0 \pm 7.8$ \\
Albumin ratio & $2.0-9.6$ & $6.0 \pm 1.8$ \\
CSF total tau & $9.0-1,200.0$ & $466.2 \pm 357.3$ \\
Plasma A $\beta_{40}, \mathrm{pg} / \mathrm{ml}$ & $21-6,848$ & $539.0 \pm 1,254.0$ \\
Plasma A $\beta_{42}, \mathrm{pg} / \mathrm{ml}$ & $5.8-221.0$ & $47.7 \pm 39.3$ \\
$\mathrm{CSF} \mathrm{A}_{40}, \mathrm{pg} / \mathrm{ml}$ & $1,534-13,676$ & $6,833 \pm 3,263$ \\
$\mathrm{CSF} \mathrm{A} \beta_{42}, \mathrm{pg} / \mathrm{ml}$ & $125-888$ & $349.5 \pm 166.9$ \\
$\mathrm{~A} \beta_{40} \mathrm{ratio}^{3}$ & $0.64-365.6$ & $83.2 \pm 95.0$ \\
$\mathrm{~A} \beta_{42} \mathrm{ratio}^{3}$ & $0.78-16.5$ & $7.7 \pm 4.1$ \\
\hline
\end{tabular}

MTA = Medial temporal lobe atrophy.

${ }^{1}$ MTA on MRI: the rating scale of Sheltens et al. [13].

${ }^{2}$ Albumin ratio $=$ CSF albumin (milligrams/deciliter) $/$ serum albumin (grams/deciliter).

${ }^{3} \mathrm{~A} \beta_{40}(42)$ ratio $=\mathrm{CSF} A \beta_{40}$ (42) (picograms/milliliter)/plasma $\mathrm{A} \beta_{40 \text { (42) }}$ (picograms/milliliter).

\section{Method}

\section{Patients}

We studied 42 consecutive patients ( 21 men/21 women) aged 53-81 years, who had consented to our study including lumbar tapping, and fulfilled the clinical criteria of the NINCDS-ADRDA Work Group for probable AD [12]. To exclude other diseases, we performed laboratory examinations including routine blood tests, CSF analyses, MRI of the brain and single photon emission computed tomography for cerebral blood flow with ${ }^{99 \mathrm{~m}}$ Tc-ethyl cysteinate dimer.

As concomitant vascular lesions would influence the BBB permeability as well as dementia, we evaluated the vascular lesions on MRI using the Age-Related White Matter Change Rating Scale [13] and excluded patients with a score of 30 or more, which indicated significant signal hyperintensity on MRI in the periventricular areas, lobar white matter, basal ganglia and infratentorial areas. The severity of dementia was assessed by Clinical Dementia Rating (CDR) and Mini-Mental State Examination (MMSE). Patients with CDR 0.5 at their first visit were included in the $\mathrm{AD}$ group if they later progressed to fulfill the $\mathrm{AD}$ criteria [12]. Informed consent was obtained from each patient under the approval of the ethics committee of the institution. The clinical features of the 42 patients are summarized in table 1 .

\section{Evaluation of Brain Atrophy on MRI}

MRI studies were performed using a 1.5-tesla unit (Signa, General Electric, N.Y., USA). For evaluation of progressive brain atrophy in $\mathrm{AD}$, we used the visual rating scale of medial temporal lobe atrophy (MTA) proposed by Scheltens et al. [13, 14]. Briefly, the 5-point rating scale (0-4) is based on assessment of the size of the hippocampal formation relative to the surrounding CSF space on coronal $\mathrm{T}_{1}$-weighted images that best depict the hippocampal formation and surrounding structures. A score of 0 was assigned when no CSF was seen surrounding the hippocampus. A score of 4 was given if there was severe atrophy of the medial temporal lobe and the normal anatomy of the hippocampus was no longer visible, with enlargement of the temporal horn and the choroid fissure. This rating scale of MTA was reported to show good interobserver reliability [15]. The patients were rated by 2 neurologists (D.Y. and K.O.) blinded to any clinical information and laboratory findings.

\section{Analysis of CSF, Serum and Plasma}

Lumbar puncture was performed to obtain CSF samples; the CSF samples were analyzed for albumin, total tau, $A \beta 1-42\left(A \beta_{42}\right)$ and 1-40 $\left(A \beta_{40}\right)$, which are major species of $A \beta$ deposited in the $\mathrm{AD}$ brain $[16,17]$, in addition to routine CSF examination. At the same time as lumbar puncture, serum and plasma samples were obtained and examined for serum albumin, ApoE isoform, and plasma $A \beta_{42}$ and $A \beta_{40}$.

The CSF/serum ratio for albumin [albumin ratio $=\mathrm{CSF}$ albumin (milligrams/deciliter)/serum albumin (grams/deciliter)] was calculated as a marker of BBB permeability [18].

For measurement of total tau, $A \beta_{42}$ and $A \beta_{40}$, CSF and plasma samples were kept frozen until the analysis. CSF levels of total tau and $A \beta_{42}$ were measured by sandwich-type enzyme-linked immunosorbent assay (ELISA) using the standard Innotest assay format (Innogenetics, Ghent, Belgium); plasma $A \beta_{42}$ was determined with the high sensitivity test format of the Innotest. CSF and plasma $A \beta_{40}$ levels were measured by sandwich-type ELISA according to the manufacturer's instructions (IBL, Gunma, Japan). Thereafter, the CSF/plasma ratios for $A \beta_{42}$ and $A \beta_{40}$ were calculated.

The ApoE isoform was determined by isoelectric focusing/immunoblotting using serum samples [19].

\section{Statistical Analysis}

The correlations of the albumin ratio with age, CDR, MMSE, MTA, CSF total tau, CSF and plasma levels of $A \beta_{42}$ and $A \beta_{40}$, and $\mathrm{CSF} /$ plasma, $A \beta_{42}$ and $A \beta_{40}$ ratios were analyzed statistically using Spearman's rank correlation test. Associations of the presence of ApoE E4 with the albumin ratio were analyzed by Mann-Whitney U test. Correlations of ApoE E4 with albumin ratio were analyzed by Spearman's rank correlation test. The level of significance was defined as $p<0.05$. Statistical analyses were performed with StatView 5.0.

\section{Results}

Albumin, total tau, $A \beta_{42}$ and $A \beta_{40}$ in CSF and serum/ plasma as well as MTA on MRI from the 42 AD patients are shown along with their clinical features in table 1.

The albumin ratio is significantly and positively correlated with MTA $(\rho=0.567, p=0.0023$; fig. $1 \mathrm{a})$ but not with age, CDR, MMSE (fig. 1b), ApoE E4 isoform, CSF total tau or CSF and plasma levels of $A \beta_{42}$ and $A \beta_{40}$. 

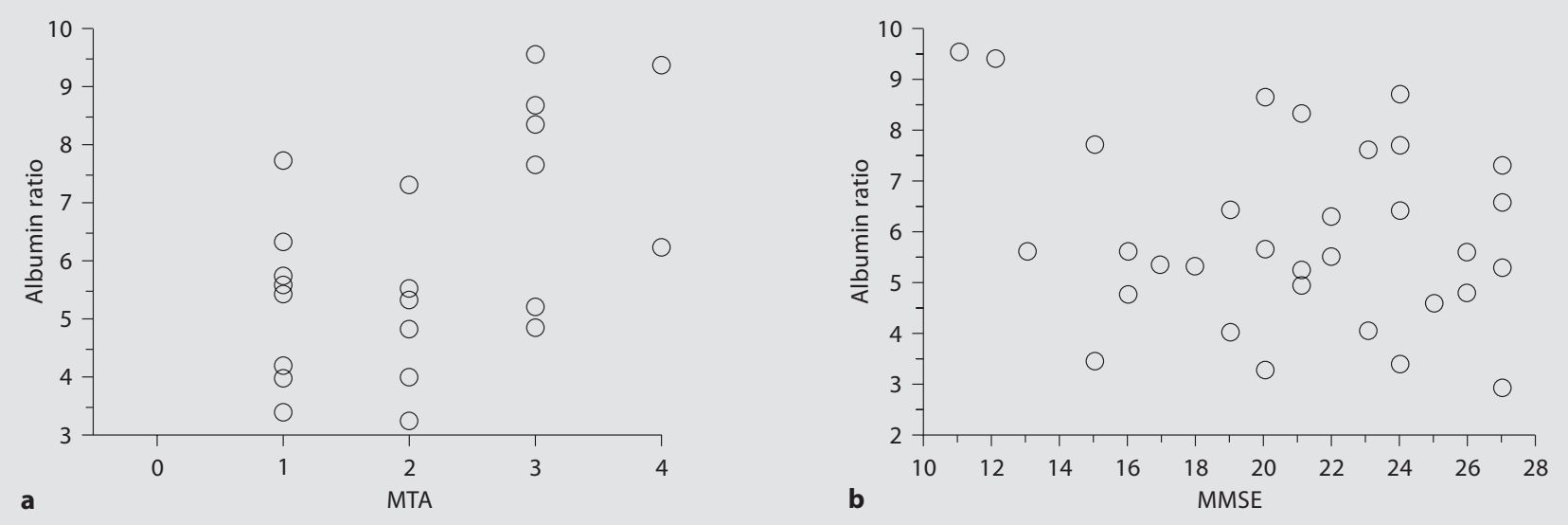

Fig. 1. Correlations between the albumin ratio (CSF/serum ratio for albumin) and severity of MTA (a), and between the albumin ratio and MMSE (b) in 42 patients with AD. See text for calculation of the albumin ratio and the MTA scoring system. The albumin ratio was significantly correlated with MTA (a) but not with MMSE (b): $\rho=0.567, \mathrm{p}=0.0023(\mathbf{a}) ; \rho=-0.089, \mathrm{p}=0.6043(\mathbf{b})$, by Spearman's rank correlation test.

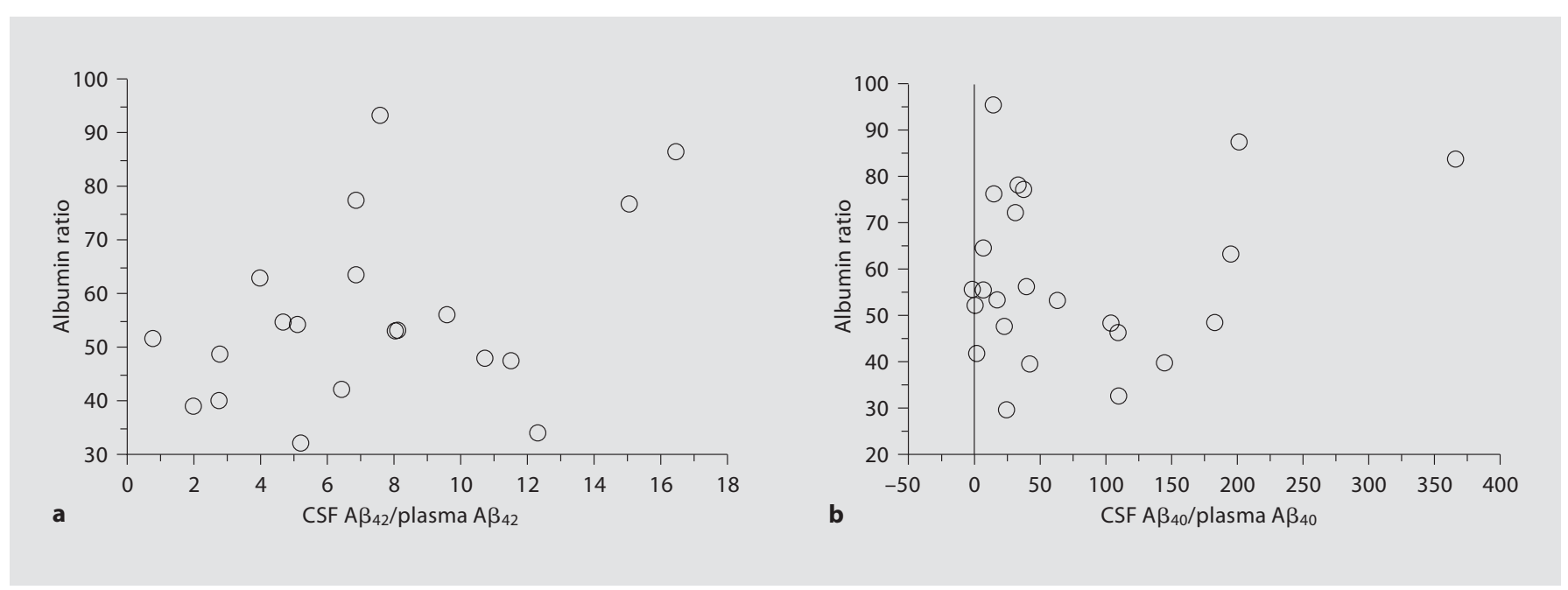

Fig. 2. Correlations between the albumin ratio (CSF/serum ratio for albumin) and CSF/plasma ratio for $A \beta_{42}$ (a), and between the albumin ratio and $\mathrm{CSF} /$ plasma ratio for $\mathrm{A} \beta_{40}$ (b) in 42 patients with $\mathrm{AD}$. No significant correlations were observed: $\rho=0.235, p=0.249(\mathbf{a}) ; \rho=-0.023, p=0.910(\mathbf{b})$, by Spearman's rank correlation test.

The CSF/plasma ratios for $A \beta_{42}$ or $A \beta_{40}$ were not correlated with the albumin ratio (fig. 2 ). In addition, there were no correlations between CSF $A \beta_{42}$ or $A \beta_{40}$ levels and those in plasma (data not shown), as reported previously [20].

Blood-Brain Barrier Permeability in Alzheimer's Disease

\section{Discussion}

Our results indicated that $\mathrm{BBB}$ permeability, evaluated as the albumin ratio, is correlated with the severity of MTA, which would represent severity of AD pathology, 
and that $C S F /$ plasma ratios for $A \beta_{42}$ and $A \beta_{40}$ are not associated with the albumin ratio.

Morphological studies of the AD brain revealed abnormalities in the brain microvasculature involving the $\mathrm{BBB}$, which could play a role in the development of $\mathrm{AD}$ $[2,6]$. However, there is little clinical evidence for breakdown of the $\mathrm{BBB}$ in $\mathrm{AD}$ patients, and the results are still controversial [1,3-5, 7-11], in contrast with cerebral ischemia and vascular dementia, in which clinical abnormalities of BBB are evident [21-23]. The albumin ratio did not differ significantly between $\mathrm{AD}$ and control cases in some reports $[4,7,9]$, while it was higher in $\mathrm{AD}$ in other reports $[3,10,11]$. Our results indicated, for the first time, that $\mathrm{BBB}$ permeability is increased in association with severity of MTA in AD.

There are several possible explanations for the conflicting results of earlier studies, including (1) no exclusion of asymptomatic cerebrovascular disease by MRI evaluation and (2) evaluation of AD severity only by dementia scales, such as MMSE. In contrast to the previous studies [3, 4, 7, 9-11], our study included only AD patients who fulfilled AD criteria [12] and had no significant vascular lesions on MRI. Further, we used not only CDR and MMSE as dementia scales but also MTA on MRI as an indicator of the severity of AD. MTA and CDR/MMSE represent different aspects of the severity of $\mathrm{AD}$. In the present study, only the MTA was correlated with the albumin ratio. The lack of correlation between CDR or MMSE and the albumin ratio in our study was consistent with a previous report [4]. Our results indicate that the $\mathrm{BBB}$ permeability changes in AD would be more closely associated with the severity of MTA, a pathological substrate characteristic of AD, than clinical severity of dementia. Our data provide clinical evidence supporting the pathological observations of microvascular abnormalities in the $\mathrm{AD}$ brain. The pathomechanisms underlying the alteration of $\mathrm{BBB}$ permeability may include microvascular degeneration, amyloid angiopathy and intrathecal inflammation that would damage BBB integrity, as demonstrated in multiple sclerosis [6, 24].

The deposition of $A \beta$, mainly $A \beta_{42}$ and $A \beta_{40}$, in the brain is an invariant neuropathological feature of $A D$, and $A D$ may arise from a chronic imbalance between $A \beta$ production and $A \beta$ clearance. $A \beta$ is detectable in soluble form in the CSF and plasma $[20,25]$. Although the turnover of $A \beta$ in CSF and plasma remains unclear, recent studies have indicated that peripheral administration of antibodies to $A \beta$ or agents with an affinity to $A \beta$ can reduce the $A \beta$ levels in the brain, most likely because of peripherally acting effects [26-28]. These observations
[26-28] suggest that $A \beta$ dynamics between the periphery and brain play an important role in the cerebral $A \beta$ deposition and provide the possibility of peripheral therapeutic approaches using such agents. Several studies have indicated that $A \beta$ transport is mediated by $A \beta$ receptors at the BBB, such as LDL receptor-related protein-1 and receptor for advanced glycation end products $[29,30]$. Our results suggest that $A \beta$ transport across the BBB is not influenced by $\mathrm{BBB}$ alterations in the $\mathrm{AD}$ brain because the $\mathrm{BBB}$ permeability represented by the albumin ratio was not related to the $C S F /$ plasma ratio for $A \beta_{42}$ or $A \beta_{40}$ in this study.

This study has some limitations; first, there were no data of control cases because of the difficulty of obtaining CSF from normal subjects; second, MTA used as a morphological marker of $\mathrm{AD}$ in this study is not specific to the disease; third, the number of patients was relatively small. Since there was no correlation of the age with MTA or albumin ratio in our 42 patients, the factor of aging does not seem to influence our results. We performed the laboratory investigations, as described in the 'Method' section, to exclude other diseases than $\mathrm{AD}$. However, further study with a larger number of $\mathrm{AD}$ patients and control subjects is necessary to confirm our results.

In conclusion, our results demonstrated, for the first time, that the BBB permeability is increased with the severity of MTA, a pathological substrate of $A D$, and that $A \beta$ transport across the BBB would not be influenced by the increased BBB permeability.

\section{Acknowledgments}

This study was supported in part by a grant for KnowledgeBased Cluster Creation Project (M.Y.) and a grant for the 21st Century COE program (on Innovative Brain Science for Development, Learning and Memory) (M.Y.) from the Ministry of Education, Culture, Sports, Science and Technology, Japan. The authors thank Ms. Y. Kakuda and Ms. Y. Yamaguchi for their excellent technical assistance. 


\section{References}

-1 Blennow K, Wallin A, Fredman P, Karlsson I, Gottfries CG, Svennerholm L: Blood brain barrier disturbance in patients with $\mathrm{Alz}$ heimer's disease is related to vascular factors. Acta Neurol Scand 1990;81:323-326.

$\checkmark 2$ Claudio L: Ultrastructural features of the blood-brain barrier in biopsy tissue from Alzheimer's disease patients. Acta Neuropathol 1996;91:6-14.

3 Elovaara I, Palo J, Erkinjuntti T, Sulkava R: Serum and cerebrospinal fluid proteins and the blood-brain barrier in Alzheimer's disease and multi-infarct dementia. Eur Neurol 1987;26:229-234

4 Frolich L, Kornhuber J, Ihl R, Fritze J, Maurer K, Riederer P: Integrity of the blood-CSF barrier in dementia of Alzheimer type: CSF/ serum ratios of albumin and IgG. Eur Arch Psychiatry Clin Neurosci 1991;240:363366.

$\checkmark 5$ Hark SL, Kalaria RN: Blood-brain barrier abnormalities in Alzheimer's disease. Ann NY Acad Sci 1991;640:47-52.

6 Kalaria RN: Small vessel disease and Alzheimer's dementia: pathological considerations. Cerebrovasc Dis 2002;13(suppl 2): 48-52.

7 Kay AD, May C, Papadopoulos NM, Costello B, Atack JR, Luxenberg JS, Cutler NR, Rapoport SI: CSF and serum concentrations of albumin and IgG in Alzheimer's disease. Neurobiol Aging 1987;8:21-25.

$\checkmark 8$ Leonardi A, Gandolfo C, Caponnetto C, Arata L, Vecchia R: The integrity of the blood-brain barrier in Alzheimer's type and multi-infarct dementia evaluated by the study of albumin and IgG in serum and cerebrospinal fluid. J Neurol Sci 1985;67:253261.

$\checkmark 9$ Mecocci P, Parnetti L, Reboldi GP, Santucci C, Gaiti A, Ferri C, Gernini I, Romagnoli M, Cadini D, Senin U: Blood-brain-barrier in a geriatric population: barrier function in degenerative and vascular dementias. Acta Neurol Scand 1991;84:210-213.

-10 Skoog I, Wallin A, Fredman P, Hesse C, Aevarsson O, Karlsson I, Gottfries GG, Blennow K: A population study on blood-brain barrier function in 85-year-olds: relation to Alzheimer's disease and vascular dementia. Neurology 1998;50:966-971.

11 Wada H: Blood-brain barrier permeability of the demented elderly as studied by cerebrospinal fluid-serum albumin ratio. Intern Med 1998;37:509-513.
12 McKhann G, Drachman D, Folstein M, Katzman M, Price D, Atadlan E: Clinical diagnosis of Alzheimer's disease: Report of the NINCDS-ADRDA Work Group under the auspices of Department of Health and $\mathrm{Hu}$ man Services Task Force on Alzheimer's disease. Neurology 1984;34:939-944.

13 Scheltens P, Barkhof F, Leys D, Pruvo JP, Nauta JJ, Vermersch P, Steinling M, Valk J: A semiquantative rating scale for the assessment of signal hyperintensities on magnetic resonance imaging. J Neurol Sci 1993;114 7-12.

14 Scheltens P, Leys D, Barkhof F, Huglo D, Weinstein HC, Vermersch P, Kuiper M, Steinling M, Wolters EC, Valk J: Atrophy of medial temporal lobes on MRI in 'probable' Alzheimer's disease and normal ageing: diagnostic value and neuropsychological correlates. J Neurol Neurosurg Psychiatry 1992; 55:967-972.

15 Scheltens P, Launer LJ, Barkhof F, Weinstein HC, van Gool WA: Visual assessment of medial temporal lobe atrophy on magnetic resonance imaging: interobserver reliability. J Neurol 1995;242:557-560.

$>16$ Andreasen N, Hesse CPD, Minthon L, Wallin A, Winblad B, Vanderstichele H, Vanmechelen E, Blennow K: Cerebrospinal fluid $\beta$-amyloid $(1-42)$ in Alzheimer disease. Arch Neurol 1999;56:673-680.

-17 Selkoe DJ: Alzheimer's disease: genotype, phenotype, and treatments. Science 1997; 275:630-631.

18 Tibbling G: Principles of albumin and IgG analyses in neurological disorder. I. Establishment of reference value. Scand J Clin Lab Invest 1977;37:385-390.

19 Kataoka S, Paidi M, Howard BV: Simplified isoelectric focusing/immunoblotting determination of apoprotein E phenotype. Clin Chem 1994;40:11-13.

20 Mehta DP, Pirttila T, Mehta SP, Sersen EA, Aisen PS, Wisniewski HM: Plasma and cerebrospinal fluid levels of amyloid $\beta$ proteins 1-40 and 1-42 in Alzheimer disease. Arch Neurol 2000;57:100-105.

21 Alafuzoff I, Adolfsson R, Bucht G, Winblad B: Albumin and immunoglobulin in plasma and cerebrospinal fluid, and blood-cerebrospinal fluid barrier function in patients with dementia of Alzheimer type and multi-infarct dementia. J Neurol Sci 1983;60:465472.

22 Pantoni L, Inzutari D, Pracucci G, Lolli F Giordano G, Bracco L, Amaducci L: Cerebrospinal fluid proteins in patients with leucoaraiosis: possible abnormalities in bloodbrain function. J Neurol Sci 1993;115: 125-131.
23 Wallin A, Blennow K, Fredman P, Gottfries CG, Karlsson I, Svennerholm L: Blood brain barrier function in vascular dementia. Acta Neurol Scand 1990;81:318-322.

24 Liebsch R, Kornhuber ME, Dietl D, Grafin von Einsiedel H, Conrad B: Blood-CSF barrier integrity in multiple sclerosis. Acta Neurol Scand 1996;94:404-410.

25 Tamaoka A, Fukushima T, Sawamura N, Ishikawa K, Oguni E, Komatsuzaki Y, Shoji $S$ : Amyloid beta protein in plasma from patients with sporadic Alzheimer's disease. J Neurol Sci 1996;141:65-68.

26 Bard F, Cannon C, Barbour R, Burke RL, Games D, Grajeda H, Guido T, Hu K, Huag J, Johnson-Wood K, Khan K, Kholodenko D, Lee M, Lieberburg I, Motter R, Nguyen M, Soriano F, Vasquez N, Weiss K, Welch B, Seubert P, Schenk D, Yednock T: Peripherally administered antibodies against amyloid beta-peptide enter the central nervous system and reduce pathology in a mouse model of Alzheimer disease. Nature Med 2000;6:916-919.

27 Demattos RB, Bales KR, Cummins DJ, Dodart JC, Paul SM, Holtzman DM: Peripheral anti-A $\beta$ antibody alters $C N S$ and plasma $A \beta$ clearance and decreases brain $A \beta$ burden in a mouse model of Alzheimer's disease. Proc Natl Acad Sci USA 2001;98:8850-8855.

28 Matsuoka Y, Saito M, LaFrancois J, Saito M, Gaynor K, Olm V, Wan L, Casey E, Lu Y, Shiratori C, Lemere C, Duff K: Novel therapeutic approach for the treatment of Alzheimer's disease by peripheral administration of agents with an affinity to $\beta$-amyloid. J Neurosci 2003;23:29-33.

-29 Deane R, Du Yan S, Submamaryan RK, LaRue B, Jovanovic S, Hogg E, Welch D, Manness L, Lin C, Yu J, Zhu H, Ghiso J, Frangione $\mathrm{B}$, Stern A, Schmidt AM, Armstrong DL, Arnold B, Liliensiek B, Nawroth P, Hofman F, Kindy M, Stern D, Zlokovic B: RAGE mediates amyloid- $\beta$ peptide transport across the blood-brain barrier and accumulation in brain. Nat Med 2003;9:907-913.

>30 Shibata M, Yamada S, Kumar SR, Calero M, Bading J, Frangione B, Holtzman DM, Miller CA, Strickland KS, Ghiso J, Zlokovic BV: Clearance of Alzheimer's amyliod- $\beta_{1-40}$ peptide from brain by low density lipoprotein receptor-related protein-1 at the blood brain barrier. J Clin Invest 2000;106:1489-1499. 